\title{
Weak* Axiom of Independence and the Non-Expected Utility Theory
}

\author{
TAPAN BISWAS \\ University of Hull
}

\section{Introduction}

The axiomatic foundation of the expected utility theory (which states that given a set of uncertain prospects individuals pick up the prospect which yields the highest expected utility) was first laid down by Von Neumann and Morgenstern (1947). Their work inspired various authors to suggest alternative sets of axioms compatible with the expected utility theory. The axiom of independence is one of the axioms which is used, either directly or indirectly, to establish the expected utility theory. This axiom has come under severe criticisms in recent years. A large number of experiments have shown that in making decisions involving uncertain prospects people frequently violate the independence axiom. In this paper we shall consider the problem of choice under uncertainty from a wider point of view and we shall examine the nature of the restriction imposed by the axiom of independence. We shall use the mean-variance utility function to prove our point. Then we shall consider a weak version of the independence axiom namely the weak* axiom of independence. This is the point of departure from the expected utility theory to the realm of the non-expected utility theory. The weak* axiom allows aversion to pure uncertainty and, in the context of the mean-variance utility theory, it is compatible with utility being an increasing function of expected returns at all levels.

\section{Choice In The Moment-Space Of Lotteries}

Consider any finite interval $[a, b]$ on the real line as the outcome (prizes) space for lotteries which may be regarded as probability distribution functions, F (.), defined on the outcome space. We consider the class of lotteries for which all moments of the corresponding distribution functions exist (some of them may be zero) and the distribution functions are uniquely defined by their moments. This uniqueness property requires some minor restrictions on the distribution functions and excludes some pathological cases [see Karlin and Shapley (1953) or Widder (1949, pp. 29-31, 60)]. We

Originally published in Economic Theory, Trade and Quantitative Economics: Essays in Honour of Professor P.N. Roy, A.Banerjee and B. Chatterjee (eds) Calcutta University Press 
define the $\mathrm{i}$-th non-central moment of a distribution as $\mu_{\mathrm{i}}=\mathrm{E}\left(\mathrm{x}^{\mathrm{i}}\right)$. The utility from an uncertain prospect $\mathrm{F}($.) may be written as a functional,

$$
\mathrm{U}=\mathrm{U}[\mathrm{F}(.)]=\mathrm{U}\left(\mu_{1}, \mu_{2}, \mu_{3} \ldots . .\right)
$$

Eq. (1) merely states that we can define the utility functions on the moment space of lotteries. We shall see that any compound lottery, $G$, involving two lotteries $F^{1}$ and $F^{2}$ with probabilities $p$ and (1-p) respectively may be regarded as a convex combination of $F^{1}$ and $F^{2}$ in the moment space of the lotteries, i.e. if

then,

$$
\mathrm{F}^{1}:\left[\mu_{1}(1), \mu_{2}(1), \ldots . .\right] \text { and } \mathrm{F}^{2}: \mathrm{U}\left[\mu_{1}(2), \mu_{2}(2), \ldots .\right]
$$

$$
\mathrm{G}:\left[\mathrm{p} \cdot \mu_{1}(1)+(1-\mathrm{p}), \mu_{1}(2), \mathrm{p} \cdot \mu_{2}(1)+(1-\mathrm{p}) \cdot \mu_{2}(2), \ldots . .\right]
$$

In order to see this we need the following theorem.

\section{Theorem 1.}

Let $\mathrm{F}^{1}$ and $\mathrm{F}^{2}$ be two arbitrary lotteries with $\mu_{\mathrm{t}}(1)$ and $\mu_{\mathrm{t}}(2)$ as their non-central moments of order $t$, then the moment of order $t$ for the compound lottery $G=\left(F^{1}, p ; F^{2}, 1-p\right)$ will be given by

\section{Proof}

$$
\mu_{\mathrm{t}}(\mathrm{G})=\mathrm{p} \cdot \mu_{\mathrm{t}}(1)+(1-\mathrm{p}) \cdot \mu_{\mathrm{t}}(2)
$$

Let $f_{1}, f_{2}$ and $g$ be the probability density functions of $F^{1}\left(x_{1}\right), F^{2}\left(x_{2}\right)$ and $G(x)$ respectively. Remember, $\mathrm{G}$ is a compound lottery yielding either of the lotteries $\mathrm{F}^{1}$ and $\mathrm{F}^{2}$ as outcome. $\mathrm{G}$ can yield a final outcome, say $\mathrm{d}$, either through $\mathrm{F}^{1}$ achieving $\mathrm{d}$ or through $\mathrm{F}^{2}$ achieving d. Therefore,

$$
\operatorname{Prob}(x=d \pm \epsilon)=p \cdot\left[\operatorname{Prob}\left(x_{1}=d \pm \epsilon\right)\right]+(1-p) \cdot\left[\operatorname{Prob}\left(x_{2}=d \pm \epsilon\right)\right]
$$

This implies that the probability density function for the compound lottery $\mathrm{G}$ is given by,

$$
\mathrm{F}_{\mathrm{G}}(\mathrm{x})=\mathrm{p} \cdot \mathrm{F}_{1}(\mathrm{x})+(1-\mathrm{p}) \cdot \mathrm{F}_{2}(\mathrm{x})
$$

Hence the non central moment of $\mathrm{G}$ for any order $\mathrm{t}$ is given by,

$$
\mu_{t}(G)=\int x^{t} \cdot f_{G}(x)=\int x^{t} \cdot\left[p \cdot f_{1}(x)+(1-p) \cdot f_{2}(x)\right] \cdot d x=p \cdot \mu_{t}(1)+(1-p) \cdot \mu_{t}(2)
$$

Originally published in Economic Theory, Trade and Quantitative Economics: Essays in Honour of Professor P.N. Roy, A.Banerjee and B. Chatterjee (eds) Calcutta University Press 


\section{BISWAS Weak*Axiom of Independence}

Henceforth, for the sake of avoiding unnecessary repetitions, the non-central moments of order $\mathrm{t}$ will be referred to simply as moments and denoted by $\mu_{\mathrm{t}}$.

Let us now turn to the independence axiom and a weaker version of it called the betweenness axiom. We shall explain how they restrict the form of the utility function in Eq. (1). Consider, three lotteries $F^{1}, F^{2}$ and $F^{3}$. Construct two compound lotteries $G^{1}$ and $G^{2}$ such that,

$$
\begin{aligned}
& G^{1}=\left(F^{1}, p ; F^{3}, 1-p\right) \\
& G^{2}=\left(F^{2}, p ; F^{3}, 1-p\right)
\end{aligned}
$$

$\mathrm{G}^{1}$ is a compound lottery with $\mathrm{p}$ as the probability of winning $\mathrm{F}^{1}$ and $1-\mathrm{p}$ as the probability of winning $\mathrm{F}^{2} . \mathrm{G}^{2}$ should be interpreted in a similar way. Following the convention used by Sen (1970) we use the symbols P, R and I to denote strict preference, weak preference and equivalence respectively. For example, $\mathrm{F}^{1} \mathrm{R} \mathrm{F}^{2}$ means $\mathrm{F}^{1}$ is weakly preferred to $\mathrm{F}^{2}$.

Axiom of Independence : $F^{1} P F^{2}$ ( or, $F^{1} I F^{2}$ ) implies $G^{1} P G^{2}\left(\right.$ or, $G^{1} I G^{2}$ )

Betweenness Axiom : $\mathrm{F}^{1} \mathrm{I} \mathrm{F}^{3}$, implies $\mathrm{F}^{1} \mathrm{I} \mathrm{F}^{3} \mathrm{I} \mathrm{G}^{1}$

The independence axiom serves as a corner stone of the expected utility theory. In an effort to generalize the expected utility theory, some authors proposed the betweenness axiom which is weaker than the independence axiom.

Let $F^{3}$ be a compound lottery $\left(F^{1}, p ; F^{2}, 1-p\right)$ where $F^{1}$ I $F^{2}$ [i.e. $U\left(F^{1}\right)=U\left(F^{2}\right)$ ].

Theorem 1 together with the betweenness axiom imply that, in the moment space of lotteries, $\mathrm{F}^{3}$ is a convex combination of $\mathrm{F}^{1}$ and $\mathrm{F}^{2}$ for any value of $\mathrm{p}$. In other words, betweenness axiom implies that the indifference curves in the moment space of lotteries are linear. Since the betweenness axiom is weaker than the independence axiom, it follows that the linearity property of the indifference curves also holds under the expected utility theory. In fact, the expected utility theory has a stronger implication, namely the functional $\mathrm{U}[\mathrm{F}()$.$] in Eq. (1) is linear.$

Let us consider an example of what we have discussed so far. Suppose, for an individual seeking to maximize his utility, only the first two moments of the distribution matters, i.e. for him $\mathrm{U}=\mathrm{U}\left(\mu_{1}, \mu_{2}\right)$. The reader should note that this is the mean-variance utility theory because of the relationship, $\sigma^{2}=\mu_{2}-\mu_{1}^{2}$. According to the expected utility theory (independence axiom), $\mathrm{U}$ is linear. Let $\mathrm{U}=\mathrm{a}+\mathrm{b} \mu_{1}-\mathrm{c} \mu_{2}$. Then we have

Originally published in Economic Theory, Trade and Quantitative Economics: Essays in Honour of Professor P.N. Roy,A.Banerjee and B. Chatterjee (eds) Calcutta University Press 
Review of Economic Analysis 4 (2012) 67-75

$$
\mathrm{U}=\mathrm{a}+\mathrm{b} \cdot \mu_{1}-\mathrm{c} \cdot \mu_{1}^{2}-\mathrm{c} \cdot \sigma^{2}
$$

The mean-variance utility theory normally assumes that individuals are risk averse. For this reason we have a negative coefficient for $\sigma^{2}$. From Eq. (3), it is clear that $U$ is not increasing in $\mu_{1}$. After a certain value of $\mu_{1}$, any increase in $\mu_{1}$ will lead to a decline in $\mathrm{U}$. This is quite unacceptable for lotteries involving financial gains. Any increase in the expected returns from the lotteries is always good news. The reason for this decline in utility is obvious. Under the expected utility theory, mean-variance utility implies that (i) either the lotteries are restricted to only normal distributions or (ii) the utility function is quadratic. We are considering a general class of distributions because a compound lottery formed out of normal distributions is, in general, not a normal distribution. A quadratic utility function, $U=a+b x-c x^{2}$ implies $\mathrm{U}=\mathrm{a}+\mathrm{b} \mu_{1}-\mathrm{c} \mu_{2}$ as above. It also implies that after a certain level of income, utility is a declining function of income, $x$.

Under the betweenness axiom, we have

$$
\mathrm{U}=\mathrm{a}(\mathrm{U})+\mathrm{b}(\mathrm{U}) \cdot \mu_{1}-\mathrm{c}(\mathrm{U}) \cdot \mu_{2}
$$

In this case, the indifference curves are linear in $\mu_{1}$ and $\mu_{2}$. However, in order to avoid any intersection of the indifference curves, another axiom called the Weak Axiom of Independence [Chew and MacCrimmon (1979)] is often invoked. It can be shown that even under betweenness, utility is not monotonically increasing in $\mu_{1}$ [Biswas (1994)]. The argument is simple. Since $\sigma^{2}=\mu_{2}-\mu_{1}^{2}$, the combinations of $\mu_{1}$ and $\mu_{2}$ which satisfy the zero variance condition $\left(\sigma^{2}=0\right)$ is given by $\mu_{1}=\mu_{2}^{2}$. When the indifference curves in the $\left(\mu_{1}, \mu_{2}\right)$ space are linear, they must twice intersect the curve satisfying the relationship $\mu_{1}=\mu_{2}^{2}$. Therefore, there are two values of $\mu_{1}$ with $\sigma^{2}=0$ which gives the same level of utility. This means $\mathrm{U}\left(\mu_{1} \mid \sigma^{2}=0\right)$ reaches a maximum for some value of $\mu_{1}$.

\section{The Weak* Axiom Of Independence}

We have seen that linear indifference curves in the moment space of lotteries have an undesirable implication. Allais (1984) argued that the expected utility theory (more precisely the independence axiom) suffers from a serious drawback. Suppose, utility $u(x)$ is an increasing function of $x$. A lottery defined on $x \in[a, b]$ also induces lottery defined on the utility space, $u \in U$, because of the monotonic relationship between $u$ and $x$. In the expected utility theory, the axioms lead to the conclusion that in comparing lotteries, only the expected utility is taken into account, whereas according to Allais, other moments of the utility distribution may play a crucial role in the choice. It is this idea which led him to construct the

Originally published in Economic Theory, Trade and Quantitative Economics: Essays in Honour of Professor P.N. Roy, A.Banerjee and B. Chatterjee (eds) Calcutta University Press 


\section{BISWAS Weak*Axiom of Independence}

famous "Allais paradox". For Allais' own formulation of a non-expected utility theory, the reader is referred to Allais (1984).

Earlier in the paper we have referred to the axiom of weak independence which runs as follows.

Axiom of Weak Independence : Consider, three different lotteries $F^{1}, F^{2}$ and $F^{3}$, such that $F^{1} I$ $F^{2}$. Given any probability ' $p$ ', there exists a probability ' $q$ ' for all possible $F^{3}$, such that $L_{1} I_{2}$ where $\mathrm{L}_{1}=\left(\mathrm{F}^{1}, \mathrm{p} ; \mathrm{F}^{3}, 1-\mathrm{p}\right)$ and $\mathrm{L}_{2}=\left(\mathrm{F}^{2}, \mathrm{p} ; \mathrm{F}^{3}, 1-\mathrm{p}\right)$.

The weak axiom of independence is weaker than the betweenness axiom but it also requires the indifference curves in the moments space of lotteries to be linear and precludes any intersection of linear indifference curves in the region of feasibility. This is not good enough if we want utility to increase with increase in certain income, $\mathrm{x}$, i.e. $\mathrm{U}\left(\mu_{1} \mid \sigma^{2}=0\right)$ increasing positively with $\mu_{1}$. With this in mind we state a weaker version of the independence axiom.

Weak ${ }^{*}$ Axiom of Independence: Consider three lotteries $\mathrm{F}^{1}, \mathrm{~F}^{2}$ and $\mathrm{F}^{3}$ such that $\mathrm{F}^{1} \mathrm{I} \mathrm{F}^{2}, \mathrm{~F}^{1} \mathrm{P}$ $\mathrm{F}^{3}$ and $\mathrm{F}^{2} \mathrm{P} \mathrm{F}^{3}$. We assume that given any probability ' $\mathrm{p}$ ', there exists a probability ' $\mathrm{q}$ ' such that $\mathrm{L}_{1} \mathrm{I}_{2}$ where $\mathrm{L}_{1}=\left(\mathrm{F}^{1}, \mathrm{p} ; \mathrm{F}^{3}, 1-\mathrm{p}\right)$ is preferred to $\mathrm{F}^{3}$ and $\mathrm{L}_{2}=\left(\mathrm{F}^{2}, \mathrm{q} ; \mathrm{F}^{3}, 1-\mathrm{q}\right)$.

The weak* axiom of independence, henceforth called the weak* axiom, rules out the possibility of strictly convex preferences. Let $\mu$ denote $\left(\mu_{1}, \mu_{2}, \ldots ..\right)$ and consider two arbitrary vectors $\mu(1)$ and $\mu(2)$ such that $\mathrm{U}[\mu(1)]=\mathrm{U}[\mu(2)]$. Preferences are said to be nonconvex if

$$
\mathrm{U}[\mathrm{t} . \mu(1)+(1-\mathrm{t}) \cdot \mu(2)] \leq \mathrm{U}[\mu(1)] ; 0<\mathrm{t}<1
$$

In case of mean-variance utility, non-convex preferences imply that the indifference curves are weakly concave in the $\mu_{1}-\mu_{2}$ plane (see figure 1 ). Note, weak concavity includes the possibility of linear indifference curves.

\section{Theorem 2}

If the weak* axiom of independence holds and $\mathrm{U}(\mu)$ is continous in $\mu$, then preferences must be non-convex everywhere in the moments space.

\section{Proof}

If preferences are not non-convex everywhere, and $U$ is continuous, there must exist a convex subspace $\mathrm{D}$ of the moments space within which the preferences are convex.

Consider $\mu(1), \mu(2), \mu(3) \in \mathrm{D}$ s.t. $\mathrm{U}[\mu(1)]=\mathrm{U}[\mu(2)]$ and $\mu(3)=\mu(1)+(1+\delta)[\mu(2)-\mu(1)]$.

Originally published in Economic Theory, Trade and Quantitative Economics: Essays in Honour of Professor P.N. Roy, A.Banerjee and B. Chatterjee (eds) Calcutta University Press 
If $\mu$ has a finite dimension, $\mu$ (3) lies on the line joining $\mu(1)$ and $\mu(2)$ and is slightly outside $\mu(2)$. Convexity of preferences imply that $\mathrm{U}[\mu(2)]>\mathrm{U}[\mu(3)]$. Consider, $\mu(4)=\mathrm{p} . \mu(1)+$ $(1-\mathrm{p}) . \mu(3)$ where $\mathrm{p}$ is close to 1 so that due to the convexity of preferences

$$
\mathrm{U}[\mu(4)]>\mathrm{U}[\mu(1)]=\mathrm{U}[\mu(2)]
$$

By the weak* axiom of independence, there must exist a 'q' such that $\mu(5)=\mathrm{q} . \mu(2)+(1-\mathrm{q})$. $\mu(3)$ and $\mathrm{U}[\mu(4)]=\mathrm{U}[\mu(5)]$. If the preferences are convex,

$$
\mathrm{U}[\mu(2)]>\mathrm{U}[\mu(4)]=\mathrm{U}[\mu(5)]
$$

because $\mu(2)$ can be expressed as a convex combination of two indifferent vectors of moments, $\mu(4)$ and $\mu(5)$. Thus we arrive at a contradiction with respect to the relationship between $\mu(2)$ and $\mu(4)$, if we allow for the convexity of preferences.

(Q. E. D.)

\section{Figure 1}

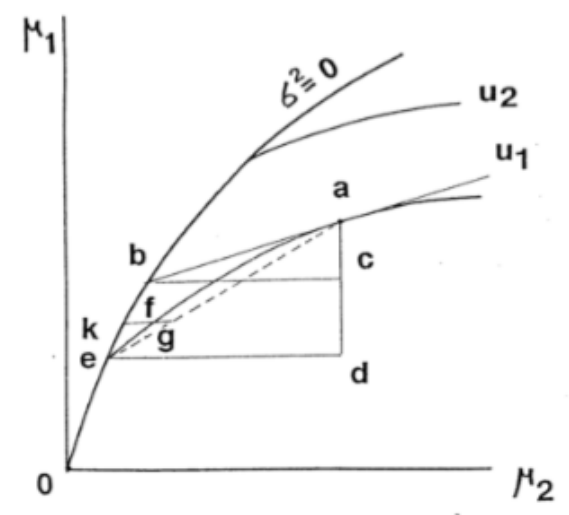

We must note that the weak* axiom of independence is closely related to an aversion of uncertainty. Even if an individual is indifferent between two lotteries, a compound lottery constructed out of the two, adds to the uncertainty by adding another step to the resolution process. According to the weak*axiom, any unnecessary complexity to the process of resolution may not be desirable and this is reflected in the non-convexity (including possible non-linearity) of preferences.

\section{Weak* Axiom, Non-Expected Utility and the Mean-Variance Theory}

Originally published in Economic Theory, Trade and Quantitative Economics: Essays in Honour of Professor P.N. Roy, A.Banerjee and B. Chatterjee (eds) Calcutta University Press 
We shall now discuss the implications of the mean variance utility theory and the role of the weak* axiom in that context. The mean variance utility theory which forms the corner-stone of portfolio analysis assumes that utility is an increasing function of expected returns and is a declining function of the variance,

$$
\mathrm{U}=\mathrm{U}\left(\mu_{1}, \sigma^{2}\right) ; \mathrm{U}_{1}>0, \mathrm{U}_{2}<0
$$

It can be shown that if $U_{1}>0$ for all values of $\mu_{1}$, and $U_{2}$ is negative for all values $\sigma^{2}$, then the indifference curves in the $\mu_{1}-\mu_{2}$ plane are concave, i.e., $\mu_{1}$ is a concave function of $\mu_{2}$ [Biswas (1994)]. For example, in portfolio theory, it is often assumed that $\mathrm{U}$ is a linear function in $\mu_{1}$ and $\sigma^{2}$ so that the indifference relationships are given by, $\mu_{1}=\alpha+\beta \cdot \sigma^{2}$. This can be simplified as

$$
\mu_{1}+\beta \cdot \mu_{1}^{2}=\alpha+\beta \cdot \mu_{2}
$$

It can be easily checked that $d_{\mu_{1}} / d_{\mu_{2}}>0$ and $d_{\mu_{1}}^{2} / d_{\mu_{2}}^{2}<0$. We have seen that the independence axiom does not allow for such a relationship and requires that along any indifference curve, $\mu_{1}$ must be a linear function of the form $\mu_{1}=\alpha+\beta . \mu_{2}$. On the other hand, weak* axiom allows for concave indifference curves by theorem 2 . Therefore Eq. (5) is plausible under the weak* axiom of independence.

Figure 1 illustrates the shape of indifference curves under the mean variance utility, satisfying the weak* axiom of independence. Horizontal distance from the curve representing, $\sigma^{2}=0$ (i.e. $\mu_{1}=\mu_{2}^{1 / 2}$ ) equals the variance of the lottery given the value of $\mu_{1}$. For example, for the lottery represented by the point $\mathrm{d}$, in figure 1 , the variance is the line segment, ed. This may be shown easily. Since $\sigma^{2}=\mu_{1}-\mu_{1}^{1 / 2}$, for a fixed value of $\mu_{1}, \Delta \sigma^{2}=\Delta \mu_{2}$. Between the points e and $\mathrm{d}, \mu_{1}$ is same. Therefore, $\sigma^{2}=$ ed. The marginal rate of substitution between expected returns and the risk (variance) at 'a' is the slope of the indifference curve at 'a'.

What is the economic significance of concave indifference curves in the $\mu_{1}-\mu_{2}$ plane? Suppose a risk averse individual is considering a purchase of stocks with different variances of returns. Since he is risk averse, he will require higher expected returns from stocks with higher variances to keep him at the same level of utility. But the rate of compensation he will seek for additional risk will decline with the level of risk he has already undertaken compensated by higher expected returns. There is no irrationality in such behaviour, although this is repudiated by the independence axiom. It is also easy to see why such behaviour is consistent with an aversion to pure uncertainty, i.e., a compound lottery composed of two indifferent alternatives is inferior to the alternatives. In figure 1 consider a certain prospect, e, and an indifferent uncertain prospect, a. A compound lottery, g, reduces the expected return and the variance proportionately. However, given the expected return at $\mathrm{g}$, the variance $\mathrm{kg}$ is

Originally published in Economic Theory, Trade and Quantitative Economics: Essays in Honour of Professor P.N. Roy, A.Banerjee and B. Chatterjee (eds) Calcutta University Press 
larger than the compensating variance kf. Clearly a proportionate fall in the variance is not enough to keep the individual on the same indifference curve. From figure 1, it is also clear that the individual's risk premium at 'a' is given by the vertical line segment, ad. Note, the concavity of the indifference curves is related to the extent of aversion to pure uncertainty, i.e., aversion to compound lotteries composed of equivalent prospects. Therefore, we would expect the risk premium under the mean variance utility to be at least as large as under the expected utility theory. In figure 1, ac measures the risk premium under expected utility theory. In this case, the indifference curves are linear and premiums decline proportionately with respect to the risk. We call ac the pure risk premium. We shall call the difference between the risk premium and the pure risk premium, cd, the uncertainty premium. If the individual is indifferent between a compound lottery composed of equivalent prospects and the prospects themselves, then the uncertainty premium vanishes and the risk premium equals the pure risk premium. Also note, when the variance is very small (risk in the small), uncertainty premium is of second order importance and the pure risk premium approximately equals the risk premium.

\section{Conclusion}

As we have seen, the weak* axiom of independence, in the context of mean variance analysis, allows aversion to pure uncertainty. But aversion to pure uncertainty need not be true in all cases. "The Doctor's Dilemma" [Sen (1986)] is an example for such a case. Suppose a doctor in the war front has two emergency patients requiring the same operation. But he has enough medical provision for the operation of only one patient. The doctor is indifferent in his choice between the two patients. The doctor can choose the patient directly and be certain of the patient to be operated upon. But he may prefer the use of a lottery of some kind for selecting the patient and thus prefer the introduction of uncertainty in the selection process. Whether a risk-averse individual is also averse to pure uncertainty or not will depend upon the context of the uncertain prospect within which he has to take a decision. Consequently, it is not likely that a simple general theory of choice under uncertainty would ever be found out. The independence axiom is an axiom which neutralizes the effect of pure uncertainty in decisions under uncertainty and simplifies the process of decision making. Unfortunately, numerous experiments have shown that the axiom fails in majority of cases and has generated a large literature on non-expected utility theories.

\section{References}

Allais M.,(1984) The Foundations of the Theory of Utility and Risk: Some Central Points of the Discussions at the Oslo Conference in Progress in Utility and Risk Theory (O. Hagen and F. Wenstop, eds.), Reidel Publishing Company: Holland.

Originally published in Economic Theory, Trade and Quantitative Economics: Essays in Honour of Professor P.N. Roy, A.Banerjee and B. Chatterjee (eds) Calcutta University Press 
Biswas T. (1994), Mean-Variance Utility and the Axioms of Independence, prepared for presentation at FUR VII conference.

Chew S.H. and MacCrimmon (*1979), Alpha-nu Choice Theory: An Axiomatization of Expected Utility, University of British Columbia, Faculty of Commerce Working Paper No. 669.

Karlin S. and L.S. Shapley (1953), Geometry of Moment Spaces, (Memoirs of the American Mathematical Society, Vol.12), American Mathematical Society.

Pryce J.D.(1973), Basic Methods of Linear Functional Analysis, Hutchinson: London.

Von Neumann J. and O. Morgenstern (1947), Theory of Games and Economic Behaviour, Princeton University Press: Princeton.

Sen A. (1986), Rationality and Uncertainty in Recent Developments in the Foundations of Utility and Risk Theory (L. Daboni, A. Montesano and M. Lines, eds.), Reidel Publishing Company.

Sen A. (1970), Collective Choice and Social Welfare, (Holden-Day Inc: London).

Originally published in Economic Theory, Trade and Quantitative Economics: Essays in Honour of Professor P.N. Roy,A.Banerjee and B. Chatterjee (eds) Calcutta University Press 